\title{
Kademeli Kayar Artımlı Şekillendirme Yöntemi ile Parça Üretiminin Optimizasyonu
}

\section{Optimization of Part Manufacturing by Multistage Rolling Blankholder Incremental Forming Method}

\author{
Ümit Önal 1®), Ömer Seçgin ${ }^{2 *}$, İbrahim Özsert ${ }^{3 \oplus}$ \\ ${ }^{1}$ Sakarya Uygulamalı Bilimler Üniversitesi, Lisansütü Eğitim Enstitüsü, Sakarya, TÜRKIYE \\ 2 Piri Reis Üniversitesi, Mühendislik Fakültesi, İstanbul, TÜRKIYE(**) \\ ${ }^{3}$ Sakarya Uygulamalı Bilimler Üniversitesi, Teknoloji Fakültesi, Sakarya, TÜRKIYYE \\ Sorumlu Yazar / Corresponding Author*: osecgin@gmail.com (**) \\ Geliș Tarihi / Received: 29.10.2019 Araștırma Makalesi/Research Article \\ Kabul Tarihi / Accepted: 15.01.2020 DOI: 10.21205/deufmd.2020226522 \\ Atıf șekli/ How to cite: ÖNAL, Ü., SEÇGIN, Ö., ÖZSERT, İ.(2020). Kademeli Kayar Artımlı Şekillendirme Yöntemi ile Parça Üretiminin \\ Optimizasyonu. DEÜFMD 22(65), 561-568.
}

Öz

Bu çalışmada kayar artımlı şekillendirme metodu kullanılarak, farklı açı artımlarıyla, kademeli şekillendirme yapılarak duvar açısı dik olan parçanın üretim optimizasyonu yapılmıştır. Çalışma kapsamında sinyal/gürültü analizi yapılarak şekillendirme kuvveti, yüzey pürüzlülügü ve et kalınlığı için ayrı ayrı optimum parametre seviyeleri belirlenmiştir. Daha sonra gri ilişkisel analiz yapılarak bu üç bağımlı değișkeni birlikte optimize eden parametre seviyeleri belirlenmiştir. Gri ilişkisel analize göre üç bağımlı değişkeni birlikte optimize eden parametre seviyeleri 9 bar sıkma basıncı, $10^{\circ}$ açı artımı, $3000 \mathrm{~mm} /$ dak ilerleme ve $0,25 \mathrm{~mm}$ artım miktarıdır. Şekillendirme kuvveti ve yüzey pürüzlülüğü için en önemli parametrenin artım miktarı, et kalınlığı için ise en önemli parametrenin sıkma basıncı olduğu belirlenmiştir.

Anahtar Kelimeler: Artımlı Şekillendirme, Kayar Artımlı Şekillendirme, Taguchi, Gri İlişkisel Analiz, Şekillendirme

\section{Abstract}

In this study, production optimization of the perpendicular part was made by using multistage forming with different angle increments by using rolling blankholder incremental forming method. Within the scope of the study, optimum parameter levels were determined separately for forming force, surface roughness and wall thickness by signal/noise analysis. Then, gray relational analysis was performed to determine the parameter levels that optimize these three dependent variables together. According to the gray relational analysis, the parameter levels that optimize the three dependent variables together are 9 bar clamping pressure, $10^{\circ}$ angular increment, $3000 \mathrm{~mm} / \mathrm{min}$ feedrate and $0.25 \mathrm{~mm}$ increment.

Keywords: Incremental Forming, Rolling Blankholder Incremental Forming, Taguchi, Grey Relational Analysis, Forming

\section{Kisaltmalar}

A: Açı artımı

F: İlerleme 
DEÜ FMD 22(65), 561-568, 2020

Fz: Düșey eksende olușan șekillendirme kuvveti

I: Artım miktar

$\mathrm{N}$ : Deney numarası

P: Sikma basincı

Ra: Yüzey pürüzlülüğü

S/N: sinyal/gürültü

T: Et kalınlığ

\section{Giriş}

Dik kenarlı sac parçalar otomotivden beyaz eșya endüstrisine, havacllıktan makine imalat endüstrisine birçok alanda kullanılmaktadır. Artımlı şekillendirme yöntemi ile dik kenarlı parça üretimi için sac farklı açlarla kademeli olarak șekillendirilir [1]. Liu ve arkadașları kademeli artımlı şekillendirme yönteminin hem deneysel hem de analitik analizini yapmıșlardır [2]. Suresh ve arkadaşları ekstra derin çekme sacını kademeli olarak şekillendirerek dik kenarlı parça üretmișlerdir [3]. $60^{\circ}$ açı ile şekillendirmeye başlayıp $70^{\circ}, 80^{\circ}, 85^{\circ}$ ve $90^{\circ}$ kademelerle șekillendirme yapmıșlardır. Shi ve arkadaşları AA1060-0 sacını 20den başlayarak kademeli olarak şekillendirmişlerdir [4]. 40 'den küçük açlarda şekillendirme yapmanın herhangi bir avantaj sağlamadı̆̆ını belirlemișlerdir. $\mathrm{Li}$ ve arkadașları $30^{\circ}$ 'den başlayarak farklı kademelerle $60^{\circ}$ açılı parça üreterek kademe sayısının artışının et kalınlığını arttırdığını belirlemişlerdir [5].

Geleneksel artımlı șekillendirme metodu ile sac metal prototip üretimi yapılabilmektedir. Anılan yöntemde sac cıvatalarla iş bağlama aparatına sabitlenir. $\mathrm{Bu}$ da et kalınlığında büyük değişikliklere neden olmaktadır. Artımlı şekillendirme yöntemi ile elde edilen parçaların et kalınlığını iyileștirmek amacıyla çeșitli çalışmalar yapılmıştır. Bu çalışmalardan biri de Seçgin ve Özsert tarafından geliștirilen kayar artımlı şekillendirme metodudur [6, 7]. Kayar artımlı şekillendirme metodunda sac cıvatalarla sabitlenmez. Sac belli bir sıkma kuvveti ile sıkılır. $\mathrm{Bu}$ kuvvet hem gerginliği sağlayacak hem de sacın akıșına izin verecek kadardır. Kayar artımlı şekillendirme metodunda sac iș bağlama aparatı üzerinde bulunan model üzerine sivanarak şekillendirilir.

Bu çalışmada yeni bir yöntem olan kayar artıml șekillendirme metodu kullanılarak $90^{\circ}$ açıl parça üretimi başarı ile yapılmıștır. Sinyal gürültü analizi yapılarak şekillendirme kuvveti, yüzey pürüzlülüğü ve et kalınlığı için ayrı ayrı parametre optimizasyonu yapılmıștır. Daha sonra gri ilişkisel analiz yapılarak her üç bağımlı değişkeni birlikte optimize eden parametre seviyeleri belirlenmiştir.

\section{Materyal ve Metot}

Bu çalışmada $1 \mathrm{~mm}$ kalınlığındaki DC01 sacı kayar artımlı şekillendirme metodu ile kademeli olarak șekillendirilmiștir. Dıș çapı $47 \mathrm{~mm}$, yüksekliği $37 \mathrm{~mm}$ olan dik kenarlı eksenel simetrik parça üretimi yapılmıştır. Üretilen parçanın tam kesit görünüşü Şekil 1'de verilmiştir.

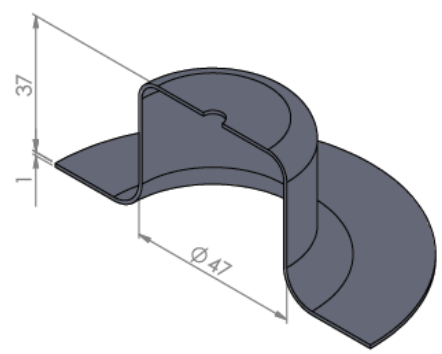

Şekil 1. Üretilen parçanın tam kesit görünüşü.

Deneysel çalışma için dört farklı parametre belirlenmiștir. Bu parametreler: sacın iș bağlama aparatına tutturulması için kullanılan pnömatik klemp sıkma basıncı (P), her bir kademede șekillendirilecek șekillendirme açısı için açı artımı (A), takımın ilerleme hızı (F) ve takımın her bir turda aşağı iniş seviyesini tanımlayan artım miktarıdır (I). Tablo 1'de deneylerde kullanılan faktörler ve seviyeleri verilmiștir.

Tablo 1. Deneylerde kullanılan faktörler ve seviyeleri.

\begin{tabular}{lcccc}
\hline \multirow{2}{*}{ Faktör } & \multicolumn{3}{c}{ Seviyeler } & \multirow{2}{*}{ Birim } \\
\cline { 2 - 4 } & $\mathbf{1}$ & $\mathbf{2}$ & $\mathbf{3}$ & \\
\hline Sıkma basıncı (P) & 2 & 5,5 & 9 & bar \\
Açı artımı (A) & 5 & 7,5 & 10 & derece \\
İlerleme (F) & 2000 & 3000 & 5000 & $\mathrm{~mm} /$ dak \\
Artım miktarı (I) & 0,25 & 0,5 & 0,75 & $\mathrm{~mm}$ \\
\hline
\end{tabular}


İs bağlama aparatına bağlanan sac önce $50^{\circ}$ açı ile şekillendirilmiștir. Daha sonra iș bağlama aparatından sökülmeden açı artım miktarı kadar daha büyük açı ile tekrar șekillendirilmiştir. $90^{\circ}$ açıya ulaşılana kadar her bir kademede açı artımı (A) kadar büyük açı ile tekrar tekrar şekillendirilerek istenilen geometriye ulaşılmıștır.

Şekillendirme deneyleri sırasında oluşan şekillendirme kuvvetleri kaydedilmiștir. Kuvvet ölçümü için Sakarya üniversitesinde geliştirilmiş olan üç eksenli kuvvet ölçme sistemi kullanılmıştır [8]. Yüzey pürüzlülüklerinin $(\mathrm{Ra})$ belirlenmesinde MarSurf PS1 yüzey pürüzlülügü ölçüm cihazı kullanılmıştır. Yüzey pürüzlülügünün belirlenmesinde "ortalama yüzey pürüzlülüğü" olan Ra değerleri dikkate alınmıştır. Et kalınlıkları ise 0,01 $\mathrm{mm}$ hassasiyetli mekanik mikrometre yardımı ile ölçülmüștür. Șekillendirilmiș olan saclar önce ortadan kesilmiş, daha sonra parça merkezinden başlanılarak beșer milimetre aralıklarla ișaretlenmiștir. İșaretlenen bu noktalardan parça kalınlıkları ölçülmüştür.

L9 ortogonal dizini kullanılarak Taguchi metodu ile deney tasarımı yapılmıştır. Daha sonra sinyal/gürültü $(\mathrm{S} / \mathrm{N})$ analizi yapılarak her bir parametrenin optimum seviyesi belirlenmiștir. Şekillendirme kuvveti ve yüzey pürüzlülüğü için Eşitlik 1'de verilen daha küçük daha iyi eşitliği kullanılırken, et kalınlığı için Eşitlik 2'de verilen daha büyük daha iyi eşitliği kullanılmıştır [9-12]. Deney tasarımı ve sinyal/gürültü analizi için Minitab programı kullanılmıştır.

$$
\begin{aligned}
& \frac{S}{N}=-10 \cdot \log \left(\frac{1}{n} \cdot \sum_{i=1}^{n} Y_{i}^{2}\right) \\
& \frac{S}{N}=-10 \cdot \log \left(\frac{1}{n} \cdot \sum_{i=1}^{n} \frac{1}{Y_{i}^{2}}\right)
\end{aligned}
$$

Eşitlik 1 ve Eşitlik 2'de n deney sayısını, $Y_{i}$ ise i indisiyle tanımlanan deneyde gözlenen veriyi temsil etmektedir. Her üç bağımlı değişken için (Şekillendirme kuvveti, yüzey pürüzlülüğü ve et kalınlığ ) parametrelerin optimum seviyeleri ayrı ayrı belirlendikten sonra gri ilişkisel analiz yapılarak bu üç bağımlı değişkeni aynı anda optimize eden parametre seviyeleri de belirlenmiștir.

Şekillendirme deneyinden bir görüntü Şekil 2.A'da verilmiştir. Deneylerde uç radyüsü 7,5 mm olan, küre uçlu form takımı kullanılmıștır.
Deneylerde kullanılan form takımı Sekil 2.B'de verilmiştir. Şekil 2.C'de ise şekillendirilmiş parça verilmiştir.

A)

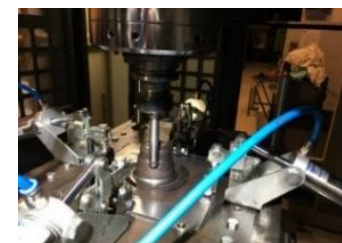

B)

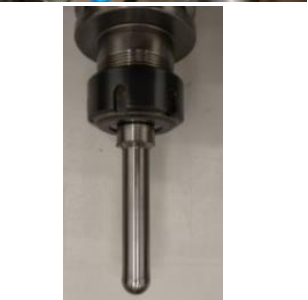

C)

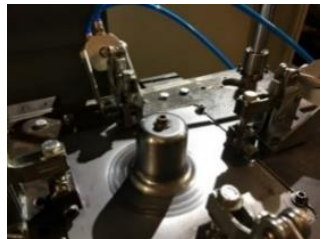

Şekil 2. Şekillendirme deneyi. A: Şekillendirme anından bir görüntü. B: Deneylerde kullanılan küre uçlu form takımı. C: Şekillendirilmiş parça.

\section{Bulgular}

\section{1. Şekillendirme kuvveti}

Şekillendirme deneyleri sırasında düşey eksende oluşan kuvvetler (Fz) Tablo 2'de verilmiştir. Tabloya göre en büyük şekillendirme kuvveti 2113,61 N'dur.

Tablo 2. Deney parametreleri, ölçülen en büyük şekillendirme kuvvetleri (Fz) ve S/N oranları.

\begin{tabular}{ccccccc}
\hline \multicolumn{5}{c}{ Deney parametreleri } & Fz & $\begin{array}{c}\text { S/N } \\
\text { oran }\end{array}$ \\
\cline { 1 - 4 } $\mathbf{N}$ & $\begin{array}{c}\mathbf{P} \\
(\mathbf{b a r})\end{array}$ & $\begin{array}{c}\mathbf{A} \\
\left({ }^{\circ}\right)\end{array}$ & $\begin{array}{c}\mathbf{F} \\
(\mathbf{m m} / \text { dak })\end{array}$ & $\begin{array}{c}\mathbf{I} \\
(\mathbf{m m})\end{array}$ & $\mathbf{( N )}$ & \\
\hline 1 & 2 & 5 & 2000 & 0,25 & 1629,25 & $-64,24$ \\
2 & 2 & 7,5 & 3000 & 0,5 & 1768,80 & $-64,95$ \\
3 & 2 & 10 & 5000 & 0,75 & 1993,33 & $-65,99$ \\
4 & 5,5 & 5 & 3000 & 0,75 & 1753,44 & $-64,88$ \\
5 & 5,5 & 7,5 & 5000 & 0,25 & 1546,23 & $-63,79$ \\
6 & 5,5 & 10 & 2000 & 0,5 & 1684,81 & $-64,53$ \\
7 & 9 & 5 & 5000 & 0,5 & 2060,66 & $-66,28$ \\
8 & 9 & 7,5 & 2000 & 0,75 & 2113,61 & $-66,50$ \\
9 & 9 & 10 & 3000 & 0,25 & 1628,92 & $-64,24$ \\
\hline
\end{tabular}


Șekil 3'de 3 numaralı deneyde olușan șekillendirme kuvvetleri grafik olarak verilmiştir. Sac ilk önce yatayla $50^{\circ}$ açıda șekillendirilmiștir. 3 numaralı deneyde açı artımı $10^{\circ}$ olduğu için daha sonra sac yatayla $60^{\circ}$ açıda şekillendirilmiştir. Sonra $70^{\circ}, 80^{\circ}$ ve $90^{\circ}$ açıda şekillendirilmiștir. Şekil 3'de de görüldüğü gibi en büyük şekillendirme kuvveti ilk şekillendirme adımında oluşmuştur. Sonraki adımlarda şekillendirme kuvveti tedrici olarak azalmıştır.

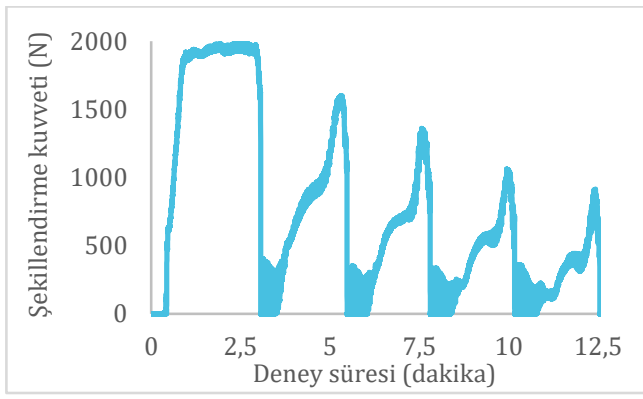

Şekil 3. 3 numaralı deneyde oluşan şekillendirme kuvvetleri.

Eşitlik 1'de verilen daha küçük daha iyi eşitliği kullanılarak yapılan S/N analiz sonuçları Tablo 3'de verilmiștir. Bu tabloda her bir parametre seviyesinin S/N oranları verilmiștir. Tablonun "Delta" satırında her bir parametrenin en büyük $\mathrm{S} / \mathrm{N}$ oranı ile en küçük S/N oranı arasındaki fark verilmiștir. "Sıra" satırında ise deltalar büyükten küçüğe sıralanmıștır. Delta değeri en büyük olan parametreye 1 numarası verilmiştir. Delta değeri en büyük olan parametre șekillendirme kuvveti için en etkili parametreyi göstermektedir. Buna göre şekillendirme kuvveti için en önemli parametre artım miktarıdır.

Tablo 3. Şekillendirme kuvveti için S/N analizi.

\begin{tabular}{ccccc}
\hline Seviye & $\mathbf{P}$ & $\mathbf{A}$ & $\mathbf{F}$ & $\mathbf{I}$ \\
\hline 1 & $-65,06$ & $-65,13$ & $-65,09$ & $\mathbf{- 6 4 , 0 9}$ \\
2 & $\mathbf{- 6 4 , 4 0}$ & $-65,08$ & $\mathbf{- 6 4 , 6 9}$ & $-65,25$ \\
3 & $-65,67$ & $\mathbf{- 6 4 , 9 2}$ & $-65,35$ & $-65,79$ \\
Delta & 1,27 & 0,21 & 0,66 & 1,70 \\
Sira & 2 & 4 & 3 & $\mathbf{1}$ \\
\hline
\end{tabular}

Şekil 4'de şekillendirme kuvveti için S/N analizi grafiği verilmiştir. Bu şekle göre şekillendirme kuvveti için optimum parametre seviyeleri 5,5 bar sıkma basıncı, $10^{\circ}$ açı artımı, $3000 \mathrm{~mm} /$ dak ilerleme ve $0,25 \mathrm{~mm}$ artım miktarıdır.

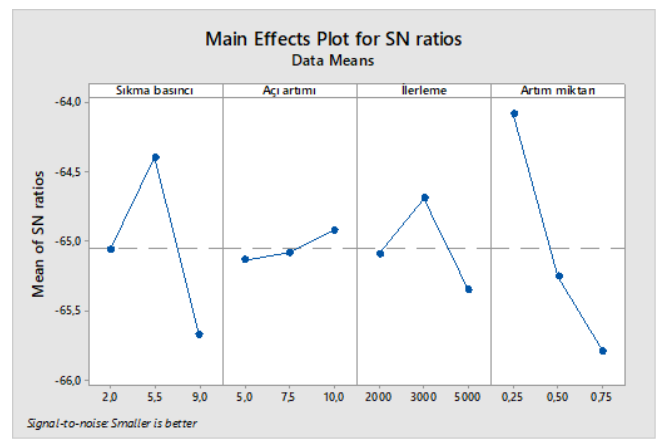

Şekil 4. Şekillendirme kuvveti için S/N analizi grafiği.

Artım miktarı şekillendirme takımının parça etrafında bir tam turunda düşey yönde aldığı yoldur. Artım miktarının büyümesi ile şekillendirilmeye zorlanan sac miktarı da büyümektedir. Bu da şekillendirme kuvvetini arttırmaktadır. Artım miktarının azalması şekillendirme kuvvetini azaltıcl etki göstermektedir.

\subsection{Yüzey pürüzlülüğü}

Parçaların yüzey pürüzlülükleri (Ra) üçer defa ölçülüp ortalamaları alınmıştır. Bu ölçümlerden elde edilen değerler ve standart sapmaları Tablo 4'de verilmiştir. Her bir deneyden elde edilen parçaların yüzey pürüzlülükleri Tablo 5 'de verilmiştir. Tabloya göre en küçük yüzey pürüzlülüğü 5. deneyde elde edilmiştir.

Tablo 4. Yüzey pürüzlülüğü ölçümlerinin

\begin{tabular}{ccccc}
\multicolumn{5}{c}{ standart sapmalarl } \\
\hline $\begin{array}{c}\text { Deney } \\
\text { No }\end{array}$ & $\begin{array}{c}\text { 1nci } \\
\text { ölcüm } \\
(\boldsymbol{\mu m})\end{array}$ & $\begin{array}{c}\text { 2nci } \\
\text { ölçüm } \\
(\boldsymbol{\mu} \mathbf{m})\end{array}$ & $\begin{array}{c}\text { 3ncü } \\
(\boldsymbol{\mu} \mathbf{\mu m})\end{array}$ & $\begin{array}{c}\text { Standart } \\
\text { sapma }\end{array}$ \\
\hline 1 & 0,476 & 0,406 & 0,404 & 0,041 \\
2 & 0,400 & 0,505 & 0,601 & 0,101 \\
3 & 0,648 & 0,718 & 0,707 & 0,038 \\
4 & 0,388 & 0,472 & 0,377 & 0,052 \\
5 & 0,229 & 0,219 & 0,259 & 0,021 \\
6 & 0,674 & 0,562 & 0,647 & 0,058 \\
7 & 0,351 & 0,363 & 0,519 & 0,094 \\
8 & 0,640 & 0,867 & 0,441 & 0,213 \\
9 & 0,316 & 0,385 & 0,335 & 0,036 \\
\hline
\end{tabular}


DEÜ FMD 22(65), 561-568, 2020

Tablo 5. Yüzey pürüzlülükleri ve $\mathrm{S} / \mathrm{N}$ oranları.

\begin{tabular}{|c|c|c|c|c|c|c|}
\hline & \multicolumn{4}{|c|}{ Deney parametreleri } & \multirow{2}{*}{$\begin{array}{c}\text { Ra } \\
(\mu \mathrm{m})\end{array}$} & \multirow{2}{*}{$\begin{array}{r}\mathrm{S} / \mathrm{N} \\
\text { oranı }\end{array}$} \\
\hline $\mathbf{N}$ & $\begin{array}{c}\mathbf{P} \\
\text { (bar) }\end{array}$ & $\begin{array}{c}\text { A } \\
\left({ }^{\circ}\right)\end{array}$ & $\begin{array}{c}F \\
(\mathrm{~mm} / \mathrm{dak})\end{array}$ & $\begin{array}{c}\mathrm{I} \\
(\mathrm{mm})\end{array}$ & & \\
\hline 1 & 2 & 5 & 2000 & 0,25 & 0,429 & 7,36 \\
\hline 2 & 2 & 7,5 & 3000 & 0,5 & 0,502 & 5,99 \\
\hline 3 & 2 & 10 & 5000 & 0,75 & 0,691 & 3,21 \\
\hline 4 & 5,5 & 5 & 3000 & 0,75 & 0,412 & 7,70 \\
\hline 5 & 5,5 & 7,5 & 5000 & 0,25 & 0,236 & 12,55 \\
\hline 6 & 5,5 & 10 & 2000 & 0,5 & 0,628 & 4,05 \\
\hline 7 & 9 & 5 & 5000 & 0,5 & 0,411 & 7,72 \\
\hline 8 & 9 & 7,5 & 2000 & 0,75 & 0,649 & 3,75 \\
\hline 9 & 9 & 10 & 3000 & 0,25 & 0,345 & 9,24 \\
\hline
\end{tabular}

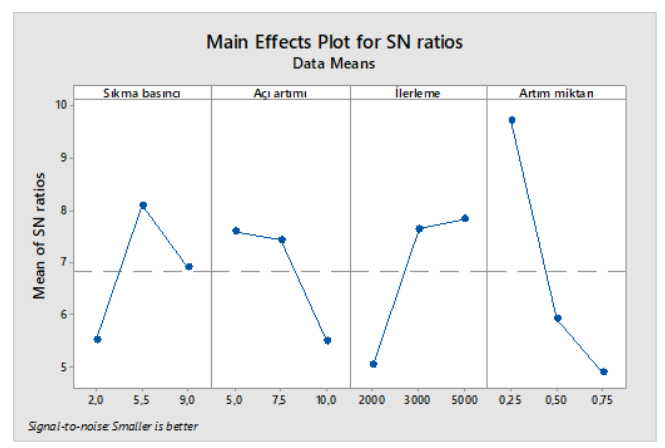

Şekil 5. Yüzey pürüzlülüğü için $S / N$ analizi grafiği.

\subsection{Et kalınlığ}

Şekillendirme deneylerinden elde edilen parçaların et kalınlıkları (t) ölçülerek kalınlık dağılımları elde edilmiştir. Daha sonra her bir parçanın en küçük et kalınlık değeri alınarak Tablo 7 oluşturulmuştur. Şekillendirme esnasında et kalınlığındaki değişimin mümkün olduğunca az olması istenmektedir. Tablo 7'de verilen et kalınlıkları listesinde bulunan en büyük et kalınlı̆̆ı değeri deneylerden elde edilen en iyi et kalınlığı olarak tanımlanmıştır. Tabloya göre en iyi et kalınlığ 2 bar sıkma basıncının kullanıldığı birinci ve üçüncü deneylerde elde edilmiştir.

Tablo 7. En küçük et kalınlıkları ve S/N oranları.

\begin{tabular}{|c|c|c|c|c|c|c|}
\hline & \multicolumn{4}{|c|}{ Deney parametreleri } & \multirow{2}{*}{$\begin{array}{c}\mathrm{t} \\
(\mathrm{mm})\end{array}$} & \multirow{2}{*}{$\begin{array}{c}\mathrm{S} / \mathrm{N} \\
\text { oranı }\end{array}$} \\
\hline $\mathbf{N}$ & $\begin{array}{c}P \\
\text { (bar) }\end{array}$ & $\begin{array}{c}\text { A } \\
\left({ }^{\circ}\right)\end{array}$ & $\begin{array}{c}F \\
(\mathrm{~mm} / \text { dak })\end{array}$ & $\begin{array}{c}\mathrm{I} \\
(\mathrm{mm})\end{array}$ & & \\
\hline 1 & 2 & 5 & 2000 & 0,25 & 0,39 & $-8,18$ \\
\hline 2 & 2 & 7,5 & 3000 & 0,5 & 0,38 & $-8,40$ \\
\hline 3 & 2 & 10 & 5000 & 0,75 & 0,39 & $-8,18$ \\
\hline 4 & 5,5 & 5 & 3000 & 0,75 & 0,37 & $-8,64$ \\
\hline 5 & 5,5 & 7,5 & 5000 & 0,25 & 0,29 & $-10,75$ \\
\hline 6 & 5,5 & 10 & 2000 & 0,5 & 0,3 & $-10,46$ \\
\hline 7 & 9 & 5 & 5000 & 0,5 & 0,37 & $-8,64$ \\
\hline 8 & 9 & 7,5 & 2000 & 0,75 & 0,27 & $-11,37$ \\
\hline 9 & 9 & 10 & 3000 & 0,25 & 0,31 & $-10,17$ \\
\hline
\end{tabular}

Tablo 7'ye göre en iyi (en büyük) et kalınlığ 2 bar sıkma basıncının kullanıldığı birinci ve üçüncü deneylerde elde edilmiștir. Tablo 8'de et kalınlığı için $\mathrm{S} / \mathrm{N}$ analizi verilmiştir. Bu tabloya göre et kalınlığı üzerinde en etkili parametre 
sıkma basıncıdır. Sıkma basıncının azalması ile daha iyi et kalınlığı elde edilmektedir.

Tablo 8. Et kalınlığı için $\mathrm{S} / \mathrm{N}$ analizi.

\begin{tabular}{ccccc}
\hline Seviye & $\mathbf{P}$ & $\mathbf{A}$ & $\mathbf{F}$ & $\mathbf{I}$ \\
\hline 1 & $\mathbf{- 8 , 2 5 4}$ & $\mathbf{- 8 , 4 8 4}$ & $-10,003$ & $-9,701$ \\
2 & $-9,949$ & $-10,176$ & $\mathbf{- 9 , 0 7 1}$ & $\mathbf{- 9 , 1 6 6}$ \\
3 & $-10,06$ & $-9,603$ & $-9,189$ & $-9,396$ \\
Delta & 1,807 & 1,693 & 0,932 & 0,535 \\
Sira & $\mathbf{1}$ & 2 & 3 & 4 \\
\hline
\end{tabular}

Şekil 6'da et kalınlığı için yapılmış olan S/N analizinin grafiği verilmiștir. Șekle göre et kalınlığı için optimum parametre seviyeleri 2 bar sıkma basıncl, $5^{\circ}$ açı artımı, $3000 \mathrm{~mm} /$ dak ilerleme ve $0,5 \mathrm{~mm}$ artım miktarıdır. $\mathrm{Bu}$ grafikten $5000 \mathrm{~mm} /$ dak ilerlemenin de iyi sonuçlar verdiği görülebilmektedir. İlerleme olarak $3000 \mathrm{~mm} /$ dak yerine $5000 \mathrm{~mm} /$ dak kullanılması işlem süresini önemli oranda azaltmaktadır.

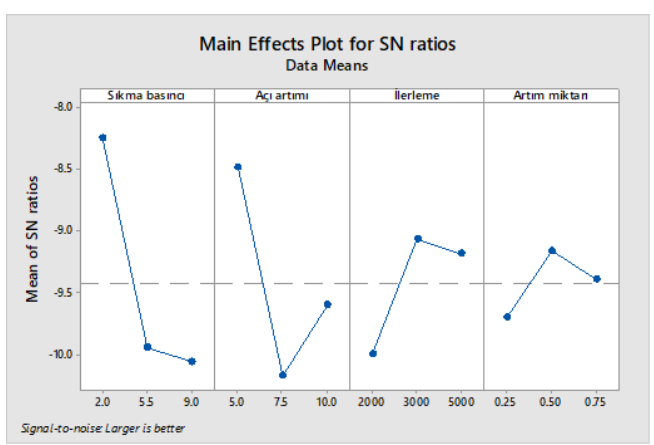

Şekil 6. Et kalınlığı için S/N analizi grafiği.

Sacı iş bağlama aparatına tutturan pnömatik klemplere uygulanan basincın azaltılması ile şekillendirme işlemi esnasında sac klemp ile iş bağlama aparatı arasından kayabilmektedir. Böylece şekillendirme esnasında sacda oluşan gerilme azalmaktadır. bu da et kalınlığının daha az incelmesini sağlamaktadır.

\subsection{Gri ilişkisel analiz}

Gri ilișkisel analiz yöntemi iki ve daha fazla bağımlı değișkenin parametre optimizasyonunda kullanılmaktadır. $\mathrm{Bu}$ çalışmada şekillendirme kuvveti, et kalınlığı ve yüzey pürüzlülüğü olmak üzere üç bağımlı değişkeni birlikte optimize etmek amacıyla gri ilișkisel analiz yapılmıștır. İlk önce șekillendirme kuvveti, et kalınlığı ve yüzey pürüzlülüğü verileri normalize edilmiștir. Normalizasyon işleminde deney sonuçarı 0 ile 1 arasına alınmaktadır. 0 en kötü sonuç, 1 ise en iyi sonucu vermektedir [13]. Bir bağımlı değişken için yüksek sonuç isteniyorsa (büyük değer daha iyi ise) Eșitlik 3 'de verilen denklem ile normalizasyon yapılır [14]. Et kalınlığının büyük olması istendiğinden normalizasyon işleminde Eşitlik 1 kullanılmıștır. Eğer küçük sonuç isteniyorsa (küçük değer daha iyi ise) Eșitlik 4'de verilen denklem ile normalizasyon yapılır. Șekillendirme kuvveti ve yüzey pürüzlülügünün az olması istendiğinden yüzey pürüzlülüğüün normalizasyonunda Eşitlik 4 kullanılmıştır. Normalizasyon işleminden sonra gri ilişki katsayısı Eșitlik 5 ile hesaplanır.

$$
\begin{aligned}
& x_{i}(k)=\frac{x_{i}{ }^{(0)}(k)-\min x_{i}^{(0)}(k)}{\operatorname{mak} x_{i}{ }^{(0)}(k)-\min x_{i}{ }^{(0)}(k)} \\
& x_{i}(k)=\frac{\operatorname{mak} x_{i}{ }^{(0)}(k)-x_{i}{ }^{(0)}(k)}{\operatorname{mak} x_{i}^{(0)}(k)-\min x_{i}^{(0)}(k)} \\
& \gamma\left(x_{0}(k), x_{i}(k)\right)=\frac{\Delta_{\min }+\delta \Delta_{\max }}{\Delta_{0 i}(k)+\delta \Delta_{\max }}
\end{aligned}
$$

3ncü ve 4ncü eşitliklerde her bir deney için normalizasyon ișlemi sonrasında elde edilen değer $x_{i}(k)$ ile gösterilmiştir. Eşitlik 3 ve Eşitlik 4'de i indisli deney için ölçüm sonucunu $x_{i}{ }^{(0)}(k)$ gösterirken, tüm deneylerden elde edilen ölçüm sonuçlarından en küçüğünü $\min x_{i}{ }^{(0)}(k)$ ve tüm deneylerden elde edilen ölçüm sonuçlarından en büyüğünü $\operatorname{mak}_{i}{ }^{\left({ }^{(0)}\right.}(k)$ göstermektedir. $5 \mathrm{nci}$ eșitlikte bulunan $\left(x_{0}(k), x_{i}(k)\right)$ ifadesinde ilk deneyden bașlamak üzere i indisli deneye kadar geçerli olan gri ilişki katsayısını temsil etmektedir. Eşitlik 5'te, genellikle $\delta \Delta_{\max }=0,5$ olarak kabul edilir. Bu eșitlikte $\Delta_{\min }$ en küçük sapma sırasıdır. $\Delta_{0 i}(k)$ ise hesaplaması yapılan deneyin sapma sırasıdır. Gri ilișkisel katsayıları hesaplandıktan sonra gri ilişkisel dereceler belirlenir. Gri ilișki derecesi, Eșitlik 6'da gösterildiği gibi her bir deneyin gri ilişkisel katsayılarının ortalamasıyla hesaplanır [13].

$$
r\left(x_{0}, x_{i}\right)=\frac{1}{n} \sum_{k=1}^{n} \gamma\left(x_{0}(k), x_{i}(k)\right)
$$

Eşitlik 6'da n cevap değişkeni sayısıdır. Gri ilișki derecesi 1'e en yakın olan deney optimum sonucu vermektedir. Tablo 9 incelendiğinde diğer deneylerle klyaslandığında 9 numaralı deneyin gri ilișki derecesinin 1'e en yakın deney olduğu görülebilmektedir. Yapılan bu çalışma 
DEÜ FMD 22(65), 561-568, 2020

için her üç bağımlı değişkeni birlikte optimize $\mathrm{mm} / \mathrm{dak}$ ilerleme, $0,25 \mathrm{~mm}$ artım ve $10^{\circ}$ açı eden parametre değerleri: 9 bar basınç, 3000 artımıdır.

Tablo 9. Gri ilișkisel analiz tablosu

\begin{tabular}{|c|c|c|c|c|c|c|c|c|c|c|c|}
\hline \multicolumn{4}{|c|}{ Deney Sonuçları } & \multicolumn{3}{|c|}{ Normalizasyon } & \multicolumn{3}{|c|}{ Gri İlişki Katsayısı } & \multirow{2}{*}{$\begin{array}{l}\text { Gri ilişki } \\
\text { derecesi }\end{array}$} & \multirow{2}{*}{ Sira } \\
\hline $\begin{array}{c}\text { Deney } \\
\text { No }\end{array}$ & $\begin{array}{l}\text { (Fz) } \\
(\mathrm{N})\end{array}$ & $\begin{array}{c}\text { Ra } \\
(\mu \mathrm{m})\end{array}$ & $\begin{array}{c}\mathrm{T} \\
(\mathrm{mm})\end{array}$ & (Fz) & $\mathbf{R a}$ & $\mathbf{t}$ & (Fz) & $\mathbf{R a}$ & $\mathbf{t}$ & & \\
\hline 1 & 1629,2 & 0,429 & 0,26 & 0,854 & 0,576 & 0,444 & 0,774 & 0,541 & 0,474 & 0,596 & 3 \\
\hline 2 & 1768,8 & 0,502 & 0,24 & 0,608 & 0,415 & 0,222 & 0,560 & 0,461 & 0,391 & 0,471 & 7 \\
\hline 3 & 1993,3 & 0,691 & 0,29 & 0,212 & 0,000 & 0,778 & 0,388 & 0,333 & 0,692 & 0,471 & 6 \\
\hline 4 & 1753,4 & 0,412 & 0,24 & 0,635 & 0,612 & 0,222 & 0,578 & 0,563 & 0,391 & 0,511 & 5 \\
\hline 5 & 1546,2 & 0,236 & 0,25 & 1,000 & 1,000 & 0,333 & 1,000 & 1,000 & 0,429 & 0,810 & 2 \\
\hline 6 & 1684,8 & 0,628 & 0,28 & 0,756 & 0,139 & 0,667 & 0,672 & 0,367 & 0,600 & 0,546 & 4 \\
\hline 7 & 2060,7 & 0,411 & 0,24 & 0,093 & 0,615 & 0,222 & 0,355 & 0,565 & 0,391 & 0,437 & 8 \\
\hline 8 & 2113,6 & 0,649 & 0,22 & 0,000 & 0,092 & 0,000 & 0,333 & 0,355 & 0,333 & 0,341 & 9 \\
\hline 9 & 1628,9 & 0,345 & 0,31 & 0,854 & 0,759 & 1,000 & 0,774 & 0,675 & 1,000 & 0,816 & 1 \\
\hline
\end{tabular}

\section{Tartışma ve Sonuç}

Bu çalışmada yeni bir yöntem olan kayar artımlı şekillendirme metodu kullanılarak farklı açı artımları ile kademeli sac șekillendirme işlemi gerçekleştirilmiştir. Sıkma basıncı, açı artımı, ilerleme ve artım miktarı olmak üzere dört farklı parametrenin şekillendirme kuvveti, yüzey pürüzlülüğü ve et kalınlığına etkileri araştırılarak ayrı ayrı optimum parametre seviyeleri belirlenmiştir. Ayrıca gri ilişkisel analiz yapılarak anılan üç bağımlı değişkeni aynı anda optimize eden parametre seviyeleri belirlenmiştir. Çalışma sonucunda aşağıdaki sonuçlara ulaşılmıştır.

- Kademeli kayar artımlı șekillendirme metodunda en büyük kuvvet ilk adımda oluşmaktadır. Sonraki adımlarda şekillendirme kuvveti tedrici olarak azalmaktadır.

- Şekillendirme kuvveti ve yüzey pürüzlülüğü için en önemli parametre artım miktarıdır.

- $\quad$ Et kalınlığı için en önemli parametre sıkma basıncıdır.

- Sıkma basıncının azalması et kalınlığını artırmaktadır.

- Şekillendirme kuvveti için optimum parametre seviyeleri:

○ 5,5 bar sıkma basıncı, $10^{\circ}$ açı artımı, $\quad 3000 \quad \mathrm{~mm} / \mathrm{dak}$ ilerleme ve $0,25 \mathrm{~mm}$ artım miktarıdır.
- Yüzey pürüzlülüğü için optimum parametre seviyeleri:

- 5,5 bar sıkma basıncı, $5^{\circ}$ açı artımı, $\quad 5000 \quad \mathrm{~mm} / \mathrm{dak}$ ilerleme ve $0,25 \mathrm{~mm}$ artım miktarıdır.

- Et kalınlığı için optimum parametre seviyeleri:

- 2 bar sıkma basıncl, $5^{\circ}$ açı artımı, $\quad 3000 \mathrm{~mm} / \mathrm{dak}$ ilerleme ve $0,5 \mathrm{~mm}$ artım miktarıdır.

- Gri ilișkisel analize göre üç bağımlı değişkeni birlikte optimize eden parametre seviyeleri:

- 9 bar sıkma basıncl, $10^{\circ}$ açı artımı, $\quad 3000 \mathrm{~mm} / \mathrm{dak}$ ilerleme ve $0,25 \mathrm{~mm}$ artım miktarıdır.

\section{Kaynakça}

[1] 1. Xu D, Malhotra R, Reddy NV, et al. (2012) Analytical prediction of stepped feature generation in multi-pass single point incremental forming. Journal of Manufacturing Processes 14:487-494. doi: 10.1016/j.jmapro.2012.08.003

[2] 2. Liu Z, Daniel WJT, Li Y, et al. (2014) Multipass deformation design for incremental sheet forming: Analytical modeling, finite element analysis and experimental validation. Journal of Materials Processing Technology 214:620634. doi: 10.1016/j.jmatprotec.2013.11.010

[3] 3. Suresh K, Prakash Regalla S, Kotkundae N (2018) Finite Element Simulations of Multi Stage Incremental Forming Process. Materials 
DEÜ FMD 22(65), 561-568, 2020

Today: Proceedings 5:3802-3810. doi: 10.1016/j.matpr.2017.11.633

[4] 4. Shi X, Hussain G, Zha G, et al. (2014) Study on formability of vertical parts formed by multi-stage incremental forming. International Journal of Advanced Manufacturing Technology 75:1049-1053. doi: $10.1007 / \mathrm{s} 00170-014-6192-\mathrm{x}$

[5] 5. Li JC, Yang FF, Zhou ZQ (2015) Thickness distribution of multi-stage incremental forming with different forming stages and angle intervals. Journal of Central South University 22:842-848. doi: 10.1007/s11771015-2591-x

[6] 6. Seçgin Ö, Özsert İ (2019) Experimental investigation of new blank holder approach for incremental forming method. International Journal of Advanced Manufacturing Technology 101:357-365. doi: https://doi.org/10.1007/s00170-018-2880-2

[7] 7. Seçgin Ö, Özsert İ (2019) DKP37 Sheet's Rolling Incremental Forming (TPIF_RL) Process Optimization by Taguchi and Response Surface Method. Duzce University Journal of Science and Technology 7:2012014.

[8] 8. Seçgin Ö, Boru B, Özsert İ (2017) Yayımlanmamış Araştırma.

[9] 9. Ayhan V, Cangal C, Cesur İ, et al. (2020) Optimization of the factors affecting performance and emissions in a diesel engine using biodiesel and EGR with Taguchi method. Fuel. doi: 10.1016/j.fuel.2019.116371

[10] 10. Altug M, Erdem M, Ozay C (2015) Experimental investigation of kerf of Ti6Al4V exposed to different heat treatment processes in WEDM and optimization of parameters using genetic algorithm. International Journal of Advanced Manufacturing Technology 78:1573-1583. doi: 10.1007/s00170-0146702-x

[11] 11. Kalyon A (2019) Elektro Erozyon ile İșlemede Yüzey Pürüzlülüğü ve İș Parçası İșleme Hızının Alüminyum Alaşımı İçin Taguchi Tekniği ile Optimizasyonu. Dokuz Eylül Üniversitesi Mühendislik Fakültesi Fen ve Mühendislik Dergisi 21:595-605. doi: 10.21205/deufmd.2019216223

[12] 12. Yılmaz CE, Aslani MAA, Aslani CK (2019) Helianthus Annuus Çekirdeği Kabuklarında Toryum Sorpsiyonunun Taguchi Metodu Kullanılarak İncelenmesi. Dokuz Eylül Üniversitesi Mühendislik Fakültesi Fen ve Mühendislik Dergisi 21:741-747. doi: 10.21205/deufmd.2019216306

[13] 13. Korucuk S (2018) Soğuk Zincir Taşımacılığı Yapan İșletmelerde 3PL Firma Seçimi : İstanbul Örneği. Iğd Üniv Sos Bil Der 16:341-366.

[14] 14. Ceviz E, Erden C (2015) Growth rate factor analysis of Turkey using Grey system theory.
Sakarya University Journal of Science 19:361369. doi: 10.16984/saufenbilder.75926 